\title{
Professional Development of the Head of an Educational Institution Within the Postgraduate Education System
}

\author{
Tetiana V. Lopukhina \\ Donetsk Regional Institute of Postgraduate Pedagogical Education \\ Olha O. Stiahunova \\ Donetsk Regional Institute of Postgraduate Pedagogical Education
}

\begin{abstract}
The purpose of the study is to search, theoretically substantiate and develop practical recommendations for the development of basic professional competencies of the head of a modern institution of general, secondary and preschool education within the system of postgraduate education. The focus of the research is the development of the professional skills of the head of a modern educational institution. The subject matter of the research is the content and conditions for the development of professional competencies of the head of a modern educational institution. The results of professional growth are a structural and functional model of professional development and preparation for managerial activities, which includes targeted, methodological, content, organisational, procedural, and affective components. The model is focused on the integration of professional, psychological, and pedagogical training of managers, where their professional and professionally diverse competencies are improved for conscious and responsible use of changes in their professional development, and solving psychological and pedagogical, and organisational and methodological tasks of corporate training of staff.
\end{abstract}

Keywords: managerial competencies, management, professional training, personal growth, pedagogy

\section{INTRODUCTION}

Currently, the development of modern society depends on education, which is necessary for human progress. It allows setting completely new requirements for all its structures (especially, for the heads of educational institutions). The main person in general education institutions is the one that has authority and is responsible for making administrative decisions. The main task of the responsible person's work is to transform the external task of the educational institution into an internal goal, and then transform the goal into an external task of the staff of educational institutions. The competitiveness of an institution on the market of educational services and the quality of education depends on the responsible person and their professional skills. The socio-economic conditions and recent innovative process in Ukrainian national development require in-depth development of education and modernisation of education management, which requires "improving the capabilities of managers at all levels" and radically changes this situation. The nature and mechanism of human interaction, priorities, ideals and values, philosophy and psychology of education, and the role of the individual in society. 
While progressing, accelerating, and experience innovative development of education and science, Ukrainian educational institutions not only need to reform the education system but to radically change the ways of managing the educational environment. The latest changes and new technologies require the head of a modern educational institution not only to learn, search and work, but also to be responsible, independent, confident, and to live and work under new requirements to adapt to society. Along with the scientific and technological progress, the professional qualifications, manager's skills, and culture set new requirements. The study defined strategic tasks of developing professional skills for managers of national level, ensuring the realisation of one's potential in personal career, and identifying main ways and approaches to qualitative renewal and optimisation of the institution's management style in general and redefining the functions and tasks of its head completely. Managerial activity affects the educational process, and means of preserving the features, development, and improvement of educational institutions. The staff of the entire educational institution cannot be dismissed.

Qualified administrative functions provide support for functional models, the appropriate structure of educational institutions, implementation of state and regional development plans for education, and the purpose of the education system. The new paradigm of career development based on the general principles of continuous education (including science, system, integrity, flexibility, predictability, and innovation) changes the forms and methods of career development, diversification of training systems, and increased one's significance. In this study, continuous education is an important prerequisite for the development of professional competency, which is provided by open educational space and is designed to meet the professional needs of particular education managers. It is possible to determine qualitative changes in the content, form, and method of continuous education for heads of general secondary education institutions by analysing the theory and practice of the postgraduate education system. These include personalisation of the educational process, productive use of media space, incorporation of teaching methods, interactive teaching methods, etc.

It is important to understand the concept of "professional competency" for its development among heads of educational institutions. Analysis of research data shows that scholars define professional competence as a certain level of integration of knowledge, proficiencies, skills, experience, and personal qualities of the head of education, thereby, ensuring the effectiveness and quality of one's professional activities. The method of functional activity can define professional ability as the head's theoretical and practical preparedness to perform professional activities. Some important features of the professionalism of the head of an educational institution that should be emphasised are professionalism, personal and professional experience, design of an individual vector for professional development; mental capacities and understanding of the essence of managerial work and procedures; understanding of the official and functional duties of the head of education, professional reliability; necessary communication method; professional reflection, anthropological abilities and establishing external and internal relations. Thus, the professional skills of administrators of educational institutions can be viewed as professional knowledge, skills, and experience that the head of a modern educational institution has. This knowledge, skills, and experience are necessary for completing official duties and professional activities by the head of an educational institution.

The purpose of the study is to search, substantiate theoretically and develop practical recommendations for the development of basic professional competencies of a head of a modern educational institution. Considering the purpose of the study, the main tasks are:

1) to determine the essence of the concept of "professional competence/development" and its components within the framework of modern research through a conceptual and comparative analysis of philosophical and psychological-pedagogical literature;

2) to analyse the development of professional knowledge and skills of the head of an educational institution and identify ways of professional and psychological and pedagogical training of managers;

3) to check conditions for the development of professional knowledge and skills of a head of a modern educational institution theoretically and practically. 


\section{LITERATURE REVIEW}

Today, the problems of management and teachers' training have not been sufficiently studied. Therefore, the works of V. Bespalko, Babansky, S. Batyshev, B. Gershunsky, and Yu. Petrov is crucial for this study. Analysis of management theory for determining the roles and positions assigned to managers shows that the problem has been sufficiently developed in economics, management, sociology, psychology, and personnel management. Yu. Yemelyanov proposes an interesting idea concerning "competence" being the level of education in the form of social and personal activities that allow a person to function successfully in society with one's believes and skills. This definition considers a person's experience, knowledge, and skills in a specific field, but the concept of "competence" has a broader meaning than that. Along with the concept of "competence", there is also the concept of "professional skill" mentioned frequently in the academic literature. In their works, scholars explain the concept of "professional competence" in different ways. The concept of "professional competence" will be discussed in more detail below.

A. Markova interprets it as "the spiritual state, which allows children to act independently and obtain human skills, the ability to perform certain labour functions". T. Brazhe explains that it is "value orientation and motivation; general culture; interaction with others; knowledge of about the outside world and own possibilities in the world; self-improvement and self-development". G. Kurdyumov defines it as "a system of knowledge, skills and abilities, professionally significant personality traits". A. Khutorskoy states that it is "a set of manager's personal qualities, which reveals the content of this personality trait within the framework of modern managerial and pedagogical activity of the head of an educational institution". The works of some well-known scholars allow viewing competence as a personal quality, one's attitude, professional, pedagogical, etc. knowledge, and skills. In modern academia, a teacher's professional skills are defined as a complex multi-level stable structure of the teacher's spiritual features. It is developed by integrating experience, theoretical knowledge, and practical skills. This is very important for the quality of the teacher's personality and defines the basic features (mobility, flexibility, and critical thinking).

The term "competence" (lat. competence - appropriate, capable) is defined as gaining knowledge in a specific professional field. The professional competence of a teacher is defined as a system of personal capabilities of a teacher, which provide an opportunity to perform professional activities independently and effectively. Therefore, the application of theoretical knowledge in practice is mandatory for the professional competency of the head of a modern educational institution. When professional competence is viewed as the ability of a qualified manager to perform certain activities, it is based on a piece of certain knowledge and skills and defines the scope of their responsibilities, so it is obvious that this category significantly differs from the conventional standard. According to I. Babin's classification, it can be defined as special. If working conditions are inappropriate, and the occupation and functions of each teacher are defined, it is impossible to perform managerial control functions, organise the educational process and distribute functional responsibilities among team members. Therefore, the establishment of the organisational structure of the educational process of any educational institution depends on the skills of the head.

\section{MATERIALS AND METHODS}

Professional competence includes interdependence and elements that necessary for increasing one's survivability. The development of managerial skills of the head of an educational institution is a systematic and ordered process focused on developing personal skills that are improved by self-development and effective work in the field of education, including the development of new professional principles. The concept of "education management" is a purposeful activity of locally operating institutions, which goal is to establish common functions to create the best working conditions and ensure a systematic mechanism for their performance. The concept of management is closely related to the concept of managerial work. "Managerial work" means the professional activity of managers in the field of education management, which has two branches: managing subordinate organisations and making legitimate, deliberate, fair, and reasonable management decisions. The professional competence of a specialist is described in modern 
academic literature as an integral feature of the business and personal qualities of specialists, reflecting the level of knowledge, proficiency, skills, and experience that are sufficient to perform a certain type of activity related to decision-making.

An important aspect for understanding the essence of the competence approach is the definition of "competence/competency" as the central concept. Analysis of the academic literature shows that there are two most common interpretations: they are either identified or differentiated. According to the first interpretation, they are presented most explicitly in the Glossary of terms of the European Foundation for Education (EFE). Competence is defined as 1) the ability to perform something well or effectively; 2) Compliance with the requirements set during employment; 3) performance of special labour functions. The source also notes that "the term competency is used in the same meanings". It is difficult to agree with this statement since N. V. Chomsky once noted within the framework of language theory that "...we make a fundamental distinction between competence (knowledge of one's language by the speaker/listener) and use (actual use of the language in specific situations)". In the above thesis, the term "use" means the actual identification of competence that is acquired by the subject, that is, competency.

The concept of basic professional competencies involves solving the problem of the interrelation between the terms "competence" and "competency". Notably, most scholars view competency as an evaluative category that describes a person as a subject of activity, one's powers, and successful performance of tasks.

Some requirements for educational institutions such as moral, intellectual, and communicative principles of system organisation are becoming a priority. This allows organising events in an economic, cultural, and social context successfully. There is a various classification of competences. Competencies are the main educational achievement in general and are interpreted as interdepartmental and cross-cultural knowledge, abilities, and skills necessary for the adaptation and production of various professional communities.

The primary competencies of leaders include the general ability to adapt to society, flexibility within modern information and cultural spaces, and creative potential. These skills should be considered universal in the field of education, and, therefore, they will contribute to free access to general European educational opportunities and services.

The modern development of society requires pedagogy and psychology to solve complex problems in order to develop tools that can contribute to the development of human studies competence (the ability to work with people, understand formal and informal relations well, create a positive moral and psychological climate, respect the human personality); democratisation of the foundations of management activities (flexibility of school organisational structures, abandonment of rigid administration, delegation of certain managerial powers to school self-government bodies, transition to democratic principles in school management, team style of management, involvement of the public in the management of a general education institution). The process of professional and psychological-pedagogical training and professional development of managers is not a conventional form of training but personal development. Therefore, there is no single method for defining the concept of competencies and the relationship between them for the professional development of the head of an educational institution.

\section{RESULTS AND DISCUSSION}

Nowadays, most higher education institutions do not prepare students for managerial activities and do not properly convey basic knowledge on professional culture as well. During the transition to multi-level training and introduction of educational and qualification levels in higher educational institutions. In

Ukraine, Masters, who have received a higher education diploma and acquired special knowledge and skills sufficient for professional innovative tasks at a certain level, are expected to hold the main positions. This activity revealed the following contradictions: a new pedagogical paradigm, the purpose of which is to train high school principals who should propagate universal and professional values, and the relatively low professional culture of modern educational institutions; European requirements for heads of educational 
institutions and the lack of scientific and reasonable teaching conditions ensure the development of due professional culture among managers in the course of advanced training.

The professional development of heads of educational institutions is crucial for the education system. The new social demands require an academic analysis of personal and professional qualities and managerial motivations of heads of educational institutions. An important aspect of understanding is the assessment of abilities and worldview, which describes people as the main complex of activities in the system of social development of labour. It considers a person's ability to make appropriate and responsible decisions in a critical situation, plan and act to achieve goals, learn from mistakes and make adjustments to the process of achieving goals. Therefore, improvement of the level of professional competency of the manager is one of the structural components of the retraining program of the Institute of postgraduate education for a teacher. A person's professional interests reveal their basic emotional needs and indicate a general attitude towards life. Therefore, tests for determining professional interest can be used not only for narrow selection tasks but also for obtaining other valuable personal information. Methods for evaluating motivation, interest, professional orientation, attitude, etc. are usually useful diagnostic tools. The main conditions for the development of professional competency for managers are presented in Table 1.

\section{TABLE 1 \\ BASIC CONDITIONS FOR THE DEVELOPMENT OF A HEAD'S PROFESSIONAL COMPETENCE}

\begin{tabular}{|l|l|}
\hline $\begin{array}{l}\text { Organisational and } \\
\text { managerial issues }\end{array}$ & $\begin{array}{l}\text { Courses, semester schedule, development of standards for determining } \\
\text { ability levels, material and technical equipment in the educational process }\end{array}$ \\
\hline $\begin{array}{l}\text { Educational and } \\
\text { methodical }\end{array}$ & $\begin{array}{l}\text { Course content selection, integration of various courses, selection of main } \\
\text { ideas }\end{array}$ \\
\hline Technological & $\begin{array}{l}\text { Room for monitoring and evaluation, active forms of organisational } \\
\text { training, identification of skills, use of innovative technologies }\end{array}$ \\
\hline $\begin{array}{l}\text { Psychological and } \\
\text { pedagogical }\end{array}$ & $\begin{array}{l}\text { System for stimulating learning motivations, defining competency } \\
\text { standards }\end{array}$ \\
\hline
\end{tabular}

Therefore, it could be concluded that development is not only equivalent to changes but also accompanied by a progressive movement of interaction between features and the environment.

The ability of heads of educational institutions to gain moral, social, and professional experience and transform abstract opportunities into true professional, ethical, social status, qualities, and functions is one of the main factors in the development of a leader's personality. The process of self-affirmation of the individual as the main governing body reflects this. This gradual process begins with basic selfdetermination, focusing on external regulators mainly, and reaches a level of self-regulation, selfexpression, and self-realisation at last. The person responsible for a modern educational institution should have such personality traits as preparation for sustainable development, creativity, interactive skills, mobility, analytical skills, forecasting skills, etc. Professional development of managers in the postgraduate education system includes gaining new knowledge in management, economics, psychology, and pedagogy. In the framework of educational innovation and development educational practice needs to implement administrative management mechanisms, especially administrative questions. There is a growing interest in management issues since the managerial activity of the head of an educational institution can improve the quality of education and organise the process to achieve the greatest effect.

A modern manager is a person who constantly strives to view their professional and personal qualities as their responsibility. The director of an educational institution must have a large number of complex management skills: setting goals, specifying goals through tasks, designing and planning the work of an educational institution, organising the educational process, diagnostics, analysis, monitoring the skills to process and make decisions based on monitoring managerial decision-making. American psychologists M. Woodcock and D. Francis believe that modern leaders need to manage themselves, a willingness to develop themselves, solve problems, creativity, the ability to influence people, leadership skills, and the ability to 
create a team. From their perspective, heads of educational institutions should possess psychological, intellectual, professional, and social qualities. The features of training of the head of an educational institution are mainly updating, complementing, and deepening existing knowledge, capturing the necessary professional knowledge, skills, qualities, responsibility, revealing relationships, and balancing official duties with specific knowledge and skills. Thus, the specific details of the preparatory work of the head of an educational institution for performing professional duties are that they should consider the specifics of management.

The head of an educational institution is a specialist who already has a certain level of development skills. However, along with the development of the Human Resource Management System, educational institutions have long been isolated from the theory of management in the field of production and operation. When manufacturing and service companies conduct business based on Human Resource Development Management, education management bodies are using the methods of traditional human resources departments of a bygone era. The consideration of the priorities of modern education requires providing new systems based on the education management system for managers of organisational professional growth. Some studies have shown that the professional skills of the head of an educational institution are similar to the skills of a teacher, but they also have specific differences, which mainly depend on the features of the functions of the manager. Therefore, skills are considered to be an integral part of the activity that includes knowledge and proficiencies. The effectiveness of the head of an educational institution is ensured not only by management personnel but also by the level of development of software components.

Considering the country's transition to market relations, the main component of educational institutions is the level of managers' qualifications. In the new socio-economic circumstances, it is necessary to change the view on the process of professional development of the head of an educational institution and the view on career development skills. This demand is defined by such factors as increasing the independence of educational institutions; increasing the responsibility of educational institutions before consumers of educational services, i.e., parents; ensuring the quality of educational services. Nowadays, along with changes in the work of educational institutions, the process of professional development of managers has been improved. As a result, there is a difference between the level of qualification of the manager and the requirements of educational institutions. Only when leaders are provided with "advanced" conditions for professional development, the system of postgraduate education for teachers can meet social expectations. Scholars associate the reserve for improving the quality of postgraduate education with solving strategic problems of the teachers' training and retraining system. These issues include achieving the integrity of the educational process in the first place. The essence of the general educational process is to make its composition and functions the main goals such as the development of a general personality of the manager.

Nowadays, scholars believe that it is necessary to move from a one-sided reflection of the leader's personality (that is, only a reflection of his professional knowledge and skills) to a description of this personality as a profession. The personal status of the manager of an educational institution, professional knowledge, and skills should be developed in a qualitatively new way. The foundation of a modern manager should be a complex system of professional and personal attitudes and stereotypes. It is important to focus all activities of postgraduate education on correcting or improving the professional beliefs and values of the leaders.

\section{CONCLUSIONS}

Improving the content of education is one of the key conditions for further perfection of professional advancement process for heads of educational institutions in the future. The learning process should not be limited to memorising facts, definitions, rules, concepts, that is, training mechanical memory. The development of managerial skills in the system of postgraduate education should be focused on the general development of a person, one's psychological function, and the development of general skills. The process of gaining, developing, and improving the managerial skill of heads of educational institutions will be effective for creating a single academic and theoretical method for professional and advanced training. Heads of educational institutions will enhance their activities in introspection, self-regulation, personal and 
professional self-development, and self-realisation. Therefore, proper organisation of the management and teaching educational process of managers will help them develop and improve their "pedagogical vision" and self-actualisation. At the same time, the result will allow people to understand the goals of their activities, develop an independent management style, develop an "I-concept" and create the foundation for an innovative manager's personality.

As for the prospects for further research in this field, the study does not cover all aspects of the research question. Further research is needed on issues related to the management of educational institutions and the development and implementation of teaching technology in higher education management.

\section{REFERENCES}

Babansky, Yu.K. (1978). How to optimise the learning process. Moscow: Znaniye.

Babin, I.I. (1997). Modular organisation of the learning process in secondary school. Thesis of the Candidate of Pedagogical Sciences. Ternopil: Ternopil State. Pedagogical University.

Batyshev, S.Y. (1997). Block-modular training. Moscow: Transservis.

Bespalko, V.P. (2007). The quality of the educational process. School Technologies, 3, 164-177.

Bilokonny, S.P. (2018). The organisation of management of the pedagogical practice is an important condition for the formation of reflective skills of the future teacher. Bulletin of Cherkasy National University, 142, 5-8.

Brazhe, T.G. (1989). Development of the teacher's creative potential. Soviet Pedagogy, 8, 89-94.

Dehtyaryova, O.A. (2017). The structure of professional competence of the head of a secondary school: A theoretical aspect. Problems of Engineering and Pedagogical Education, 56-57, 40-48.

Gershunsky, B.S. (1998). Philosophy of education. Moscow: Moscow Psychological and Social Institute.

Kalinina, H.M. (2017). Discourse analysis of concepts of public administration by school principals. In Annotated results of research work of the Institute of Pedagogy of the National Academy of Pedagogical Sciences of Ukraine for 2017 (pp. 222-223). Kyiv: Pedahohichna dumka.

Khutorskoy, A.V. (2003). Key competencies as a component of the personality-oriented paradigm of education. Public Education, 2, 58-64.

Kot, O.O., Milovska, N.V., \& Yefimenko, L.V. (2021). Methodological foundations of legal education reform in Ukraine: Scientific paradigm and modern context. Journal of the National Academy of Legal Sciences of Ukraine, 28(2), 114-122.

Kurdyumov, G.M. (1994). About the formation of personal qualities of future specialists. Higher Education in Russia, 2, 103-105.

Lunyachek, V.Y. (2018). Professional development of education leaders in Ukraine: Methodological component. New Pedagogical Thought, 2(94), 14-22.

Markova, A.K. (1990). Psychological analysis of the teacher's professional competence. Soviet Pedagogy, 8, 82-88.

Marmaza, O.I. (2017). Management in education: The road map of the head. Kharkiv: Osnova.

Petrov, Y.N. (1994). Model of continuing professional education. Ninzhny Novgorod: VIPI.

Skotsyk, V. (2017). How do we live in an era of change? Kyiv: Summit-knyha.

Voronova, S.V. (2018). Coach technology for school principals. Kharkiv: Osnova.

Vozniuk, L. (2013). The role of the education manager in the renewal of the modern school. Problems of Modern Teacher Training, 8(1), 180-185.

Woodcock, M., \& Francis, D. (1991). The unblocked manager. Moscow: Delo.

Yakuhno, I.I. (2020). Scientific bases of innovative development of postgraduate pedagogical education. Zhytomyr: Polissya.

Yemelyanov, Y.N. (1991). The theory of formation and practice of improving communicative competence. Thesis of the Candidate of Psychological Sciences. Saint Petersburg: Saint Petersburg State University.

Zimnyaya, I.A. (2004). Key competencies as an effective-target basis for a competence-based approach in education. Moscow: Research Center for the Problems of the Quality of Training of Specialists. 